\title{
Schauder's type of fixed point theorem in locally convex space
}

\author{
Andrzej Nowakowski ${ }^{1}$ and Robert Plebaniak ${ }^{1}$ \\ ${ }^{1}$ University of Lodz Faculty of Mathematics and Computer Science
}

August 19, 2020

\begin{abstract}
We introduce the concept of generalized norm in linear vector spaces which extends the classical norm. Using that generalized norm we provide a generalization of Schauder's type theorem. Next we give some applications of this theorem to find solutions of initial value problems.
\end{abstract}

\section{Hosted file}

Manuscript1.pdf available at https://authorea.com/users/352279/articles/476609-schauder-stype-of-fixed-point-theorem-in-locally-convex-space

\section{Hosted file}

Manuscript1.tex available at https://authorea.com/users/352279/articles/476609-schauder-stype-of-fixed-point-theorem-in-locally-convex-space 